\title{
A NOTE TO THE READER
}

\section{1}

HERE IS no standard English translation of the Guide to Bodhisattva Practice (Bodhicaryāvatāra). Each author in this volume makes plain which translation is being cited in her or his chapter. Unless otherwise noted, chapter and verse citations (e.g., 4.5) refer to traditional numbering (and not to Dunhuang versions). For advice and discussion of some widely used English translations, see "Appendix I: A Guide to Guide Translations: Advice for Students and Instructors."

Different authors also use different translations of certain technical terms, such as "thought of enlightenment" or "Mind of Awakening" for the term bodhicitta. Each of these translations appears in the index, and each refers the reader to the index entry for the original Sanskrit, which in turn lists all of the translations and their various locations in the book. 
